\title{
Development of Strategies to Prevent Third Rail Insulator Failures in Transit Systems
}

\author{
Behzad Rouhanizadeh $^{1} \cdot$ Sharareh Kermanshachi $^{1}$
}

Received: 5 September 2020/Revised: 4 February 2021/Accepted: 15 February 2021/Published online: 24 March 2021

(C) The Author(s) 2021

\begin{abstract}
Failures of third rail insulators, which often impose problems that affect the serviceability of transit systems, rarely have been investigated. This study examines various aspects of third rail systems, identifies causes of insulator failures, and develops and categorizes preventive strategies. To accomplish the goals, the existing literature was reviewed and analyzed to identify various characteristics of third rails and insulators. Then, five transit case studies were analyzed to determine the characteristics of third rails, identify the causes of insulator failures, and evaluate the preventive strategies adopted by transit agencies. The results revealed that local environmental conditions cause degradation of insulators, with dirt build-up being the biggest contributor to failure. Performing maintenance and inspections of insulators at predetermined intervals was also shown to be very effective for preventing failure. The preventive strategies were classified into three categories: regular inspections; preventive maintenance programs; and regulation and safety, with regular inspections being the most frequently adopted. Findings of this study will serve as an appropriate source of information for practitioners who work with third rail systems and will help them adopt effective strategies.
\end{abstract}

Sharareh Kermanshachi

sharareh.Kermanshachi@uta.edu

Behzad Rouhanizadeh

behzad.rouhanizadeh@mavs.uta.edu

1 Department of Civil Engineering, University of Texas at Arlington, 425 Nedderman Hall, 416 Yates Street, Arlington, TX 76019, USA

Communicated by Ahmed Mohamed.
Keywords Third rail · Transit system · Rail failure · Strategies

\section{Introduction}

Rail networks have been critical components of transportation systems and the economy worldwide for more than 150 years, particularly in urban areas [1]. In the United States, railways deliver five million tons of freight every day and transport one-third of market trading [2]. Urban areas are served by electric trains of different voltages, and are categorized as light rail or heavy rail systems according to their power-providing system. A light rail system usually is powered by a $750 \mathrm{~V}$ positive overhead catenary wire, with the running rails providing the negative return circuit. In heavy rail systems the power is $750 \mathrm{~V}$ positive and carried through the third rail, and the running rails provide the negative return.

The third rail is originally American, and its use dates back to the dawn of the first subway system in the 1860s. Some railway power supply systems are limited to using overhead contact lines because their voltage levels are above $1 \mathrm{kV}$; however, third rails provide electric power to a railway vehicle by a rigid conductor that is placed between or along the rails [3]. The train runs from the power drawn from the third rail, which is usually found near the tracks [3] and carries a high voltage that is extremely dangerous if touched.

Electric railway vehicles receive their power from the pantograph-catenary system (in overhead contact lines) and the collector shoe (in third rail systems). The collector shoe used in third rail systems has many advantages over the pantograph-catenary system, such as lower cost, less required maintenance, a longer service life, and less impact 
on the landscape [4]. Third rails are also more compact, making them more practical for tunnels with small diameters, and they use one contact variant among the top contact, side contact, and bottom contact. The top contact is less safe than the other two and is susceptible to interruptions due to ice and snow.

Most of the research on third rail systems has been based on the low-speed level (about $80 \mathrm{~km} / \mathrm{h}$ ), but a few researchers have concentrated on the high-speed $(120 \mathrm{~km} /$ h) condition and the reduction of third rail failures [5]. Vohra [6] conducted research through which the data pertaining to the contact force and the displacement of the collector shoe were analyzed, and the vibration rule of the shoe was obtained by combining the circular third rail test rig and the vehicle test device. The results indicated that if the collector shoe stops functioning, it can cause the shoe to veer off from the third rail. Kumosa et al. [7] analyzed the characteristics of the third rail slider by establishing the matching characteristic model of the contact surface and the third rail and identifying the factors that affect the running speed of the collector. Several researches illustrated the characteristics of normal contact stiffness on the contact surface of the third rails and analyzed the impact on the vibration response of the collector system $[3,6]$.

Insulators used for protecting third rails can be made of various materials, including wood, porcelain, and fiberglass, and may be a variety of dimensions [6]. It is difficult to design a standard cleaning device for them because of the differences in types and sizes [6], but one solution is to design an adjustable cleaning device that can accommodate the different insulator sizes [8]. Mobasher et al. [9] examined the glass-reinforced plastic (GRP) rods used in the insulators to detect microscopic defects, and the results demonstrated that chemical reactions promote cracks in the rods and play a major role in the failure process. When Montesinos et al. [6] studied micro-cracks in the same types of rods, they found that the performance of GRP insulators can be affected by environmental conditions.

Third rail insulators are frequently damaged by material corrosion caused by electrical erosion and dirt accumulation [8]. Dirt build-up, erosion, cracks, etc. are the most frequent insulator failure causes [4]. The common preventive strategies to reducing third rail insulator failures are cleaning the insulators and the surrounding area at consistent intervals, regular inspections, and preventative maintenance [10]. Cherney et al. [11] researched insulators that come in contact with a direct current (DC) and recommended conducting an erosion test to identify erosion in the insulating materials. Stewart [4] conducted a dynamic analysis of the corrosion caused by leakages in nongrounded DC railway systems.

In any electric railway system, including third rail systems, a good current-collecting condition is a prerequisite for ensuring that the vehicle's performance is safe, reliable, and stable. It can also reduce the costs of maintaining the system and decrease the amount of damage done to the current-collector components [10]. The expansion of the metro line networks and the greater number of passengers that are being transported have increased the running speed of the vehicles and resulted in higher requirements for the current-collecting performance of the vehicles in highspeed and complex environments. This makes it important to study the performance of the third rails so that improvements can be made that will reduce the rate of their failures, specifically insulator-related failures. The aims of this study were to (1) investigate the characteristics and issues of third rails, (2) identify the causes of third rail insulator failures, (3) identify strategies for mitigating third rail insulator failures, and (4) categorize the identified strategies. The results of this study can be used by transit agencies to improve the performance and reduce the costs of their third rail systems.

\section{Research Methodology}

A five-step methodology was developed to accomplish the objectives of this study, as is shown in Fig. 1. In the first step, existing literature related to third rail characteristics, causes of failure, and preventive strategies was collected. The database included peer-reviewed articles, conference papers, books, reports, and theses published by academicians, experts, and professionals who work on third rail systems and insulators.

In the second step, the collected documents were analyzed for content to determine the third rail characteristics, arrangements, mechanisms, material types, advantages and disadvantages, causes of failure, and preventive strategies. In the third step, five case studies of third rail systems were collected, and in step four, the collected case studies were examined in detail and their characteristics, causes of failure and associated costs, and preventive strategies were analyzed. In step five, the case studies were discussed, and their characteristics and adopted strategies were comparatively analyzed.

\section{Literature Content Analysis}

According to the literature, third rail systems are one of the oldest means of supplying electric power to trains [10]. While many metro systems utilize overhead wires, third rails can be an appropriate choice when the power is supplied by DCs with voltage less than $1000 \mathrm{~V}$ [1]. Technically, a third rail is a means of supplying a traction current to a traction unit such as a train. The power of the system is 
Fig. 1 Research methodology framework

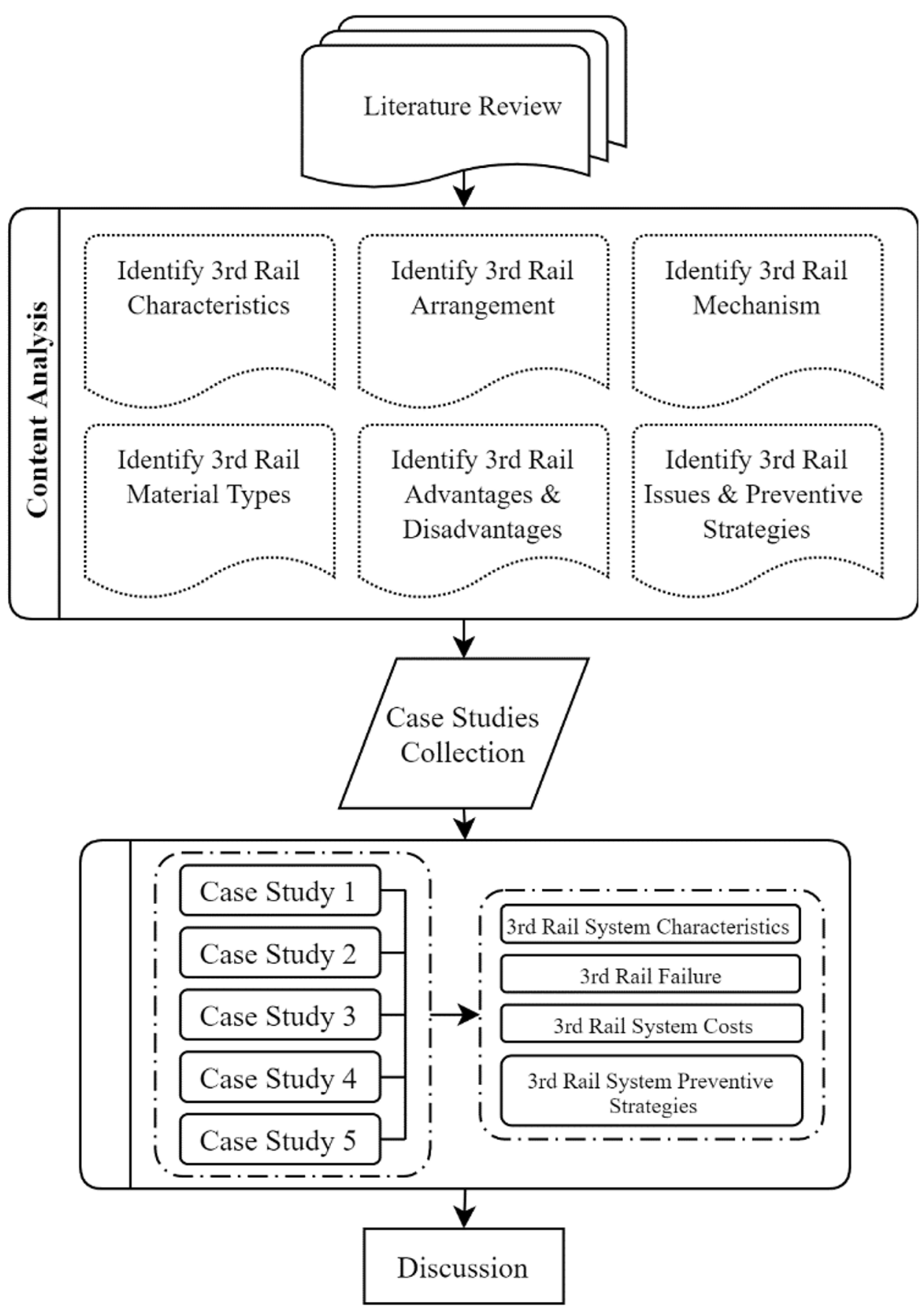

collected by a shoe that is mounted on a beam and located on its side. In Fig. 2, a third rail system is demonstrated schematically.

Third rails can be of several different shapes and can be placed either outside the rails or between them to transmit current to the moving train. The current is transmitted to the train by a sliding connection that is composed of springs and pistons, and a shoe gear. The material used for the shoe gear varies according to the material of the third rail [12].
To minimize resistance in the electric circuit, the running rails are usually connected by wire bonds or other tools. The contact position between the train and the rail varies. A top contact was used in the earliest transit systems, but a side or bottom contact was used in transit systems that were developed later [13]. Both the side contact and bottom contact cover the conductor rail, protect track workers, and protect the conductor rail from dirt, snow, ice, etc. Contact shoes can be positioned anywhere around the third rail, depending on the third rail type [13]. 
Fig. 2 Schematic sections of a third rail

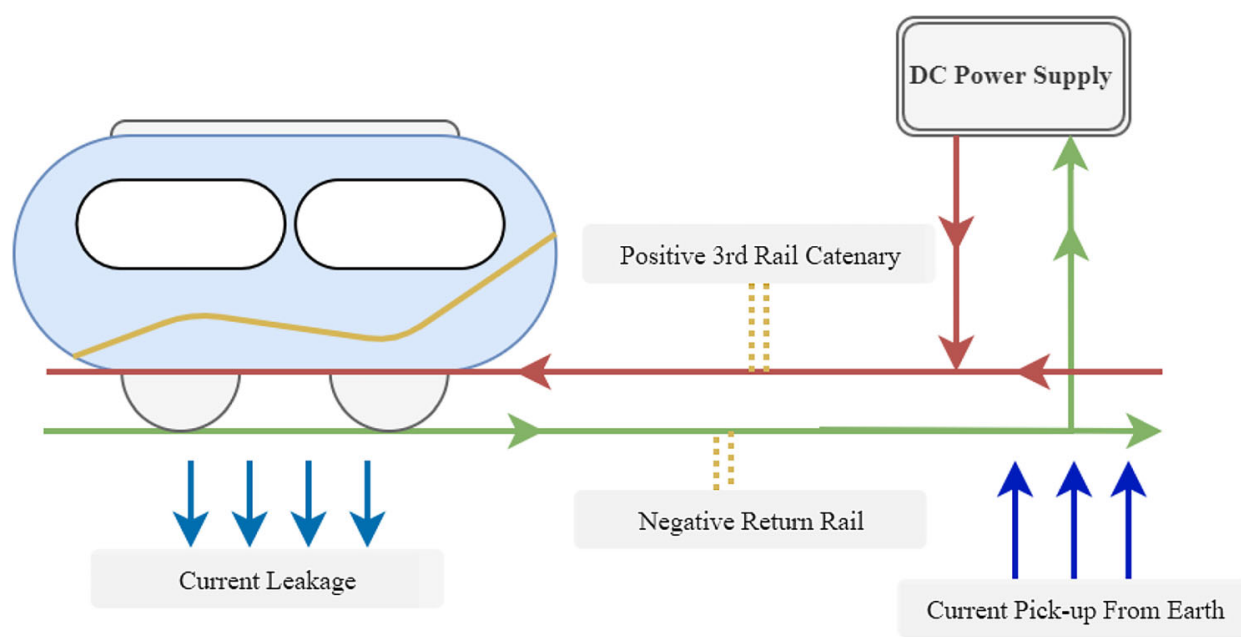

In the USA, conductor rails are mostly made of steel in order to boost conductivity. In other parts of the world, conductors are made of extruded aluminum with a stainless-steel contact surface because of its longer life, low electrical resistance, and light weight [14]. Several countries, such as South Korea, Japan, and Spain, are adopting overhead wires across urban railroads, but many new third rail systems have been established all around the world, including many advanced countries such as Denmark, Taiwan, and China [15]. In the following, the third rail characteristics are presented from different aspects.

\subsection{Third Rail Arrangement}

Third rails consist of running rails, insulators, protection boards, protection board brackets, and shoe contacts. Fig. 3 shows the placement of these sections.

\subsubsection{Running Rails}

The fundamental method employed to transmit electricity to trains is to use the rails that the train runs on. Every rail serves as a conductor, and the sleepers are supposed to act as insulators [16]. This method does not work well for large trains, however, because the sleepers do not work properly as insulators for them. In addition, insulated wheels are needed for the electric connections, and most of the metal materials used for this purpose are mechanically inferior [17].

\subsubsection{Insulators}

Contact rail insulators are usually made of fast-drying, nonconducting materials such as porcelain, fiberglass, or composite materials, and are installed at each supporting bracket $[18,19]$. Rubber insulators are increasingly used for transmission lines and have several advantages over
Fig. 3 Third rail position in the railway system and other relative equipment

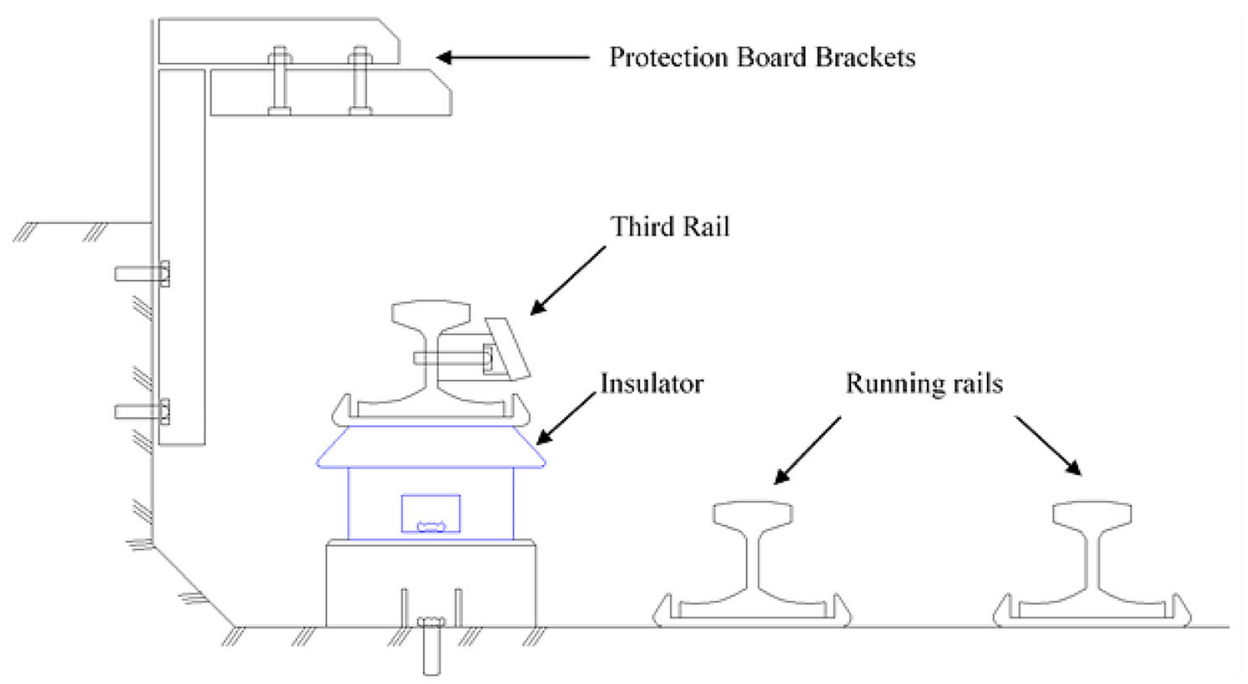


conventionally used insulators, as they are lightweight, have a slim design that is resistant to vandalism, and cause less pollution in the environment. These insulators include three components: fiber-reinforced plastic (FRP), metal end fittings, and silicone rubber $[18,20]$. The primary concern of using them is the deterioration of the material properties caused by aging.

\subsubsection{Protection Board}

Protection boards cover the top of the railway's electric third rail and are settled on the contact rail to protect personnel from coming in contact with the rail $[19,21]$. These boards are typically made of fiberglass, plastic, and timber [15].

\subsubsection{Protection Board Brackets}

The protection board brackets are located above the ties to support the protection board on the contact rails. Each of the brackets slides gently onto the rail, is fitted over a board, and is mounted to it [22].

\subsubsection{Shoe Contact}

Although third rails are usually placed outside the running rails, they are located between the two third rails in some cases. A sliding shoe that is in contact with the rail is used to transmit electricity to the train. The shoe contact connects the side and bottom of the third rails and allows a protective cover to be mounted to the top surface. This shoe is technically referred to as "top-running" when the shoe slides on the top surface, and "bottom-running" when it slides on the bottom surface. Snow and ice have less impact on the bottom-running shoe $[5,18]$, which negates the possibility that someone could be electrocuted.

\subsection{Third Rail Mechanism}

Third rails can collect current by a variety of methods and designs. The top contact method is the most modest and oldest; however, practitioners and experts in third rails have identified several drawbacks to this method [23]. The safety risk of the exposed electric conductor is very high; the top contact collects leaves and ice, causing them to be inoperable; and the remedies for resolving this problem are costly. The bottom contact method is considered by most to be the best approach for third rail current collection, as most parts of the rail are covered and protected from environmental issues [24].

The third rail shoe acts as a conductor power feed and has a ground return. Typically, the wheel to the connection of the rail works as a return, and the rail's natural contact to the earth forms the return path. Sometimes, when the abovementioned return circuit is deemed unsafe, a fourth rail is added as the return component. Even though using a third rail does not necessarily require the utilization of DC, all of them use it, as it has the potential to carry more power than an alternating current (AC) system that is operating at a similar voltage [25].

\subsection{Third Rail Material Types}

Three conventional types of rails are currently utilized in third rail systems: steel, aluminum, and aluminum/stainless (ALSS) [14]. Steel rails, which date back to the 1890s, are the traditional technology used for this purpose and are used for a majority of the third rails that are operating in the USA [26]. They have the longest performance time and have been serving reliably in many third rail systems for several decades. Aluminum, bonded by bolts or rivets to a steel rail conductor, allows matching the size to the steel rail and has lower electrical resistance than the steel rail. It is widely used for third rail systems in the USA. Aluminum/stainless is also used for this purpose [14]. It was initially introduced in the USA during the 1960s and consists of a stainless-steel cap that is affixed to an aluminum extrusion. More than $4000 \mathrm{~km}$ of ALSS conductors are currently in operation worldwide [26]. Materials and composites, such as bulk molding compound (BMC), GRP, fiberglass, wood, porcelain, etc. are used to make third rail insulators [13]. The performance of composite insulators initially depends on the restrictions of the local environment. Rapid rail transit systems implement such insulators, which are typically placed internally at a distance of $3 \mathrm{~m}$ and are used in many areas of the world [13].

\subsection{Third Rail Advantages and Disadvantages}

The major advantages and disadvantages of third rails and their sources are presented in Table 1. Their use is limited in railway systems because of the small tensions that can run and the voltage limitations that constrain the size and speed of the trains $[4,27,28]$. As an illustration, because of electricity limitations, trains that utilize third rail systems can provide limited amounts of air conditioning, which of course affects the passengers' comfort level. Experience has shown that $100 \mathrm{mph}$ is the highest speed possible by third rails. Above this speed, shoe and rail contact might face problems, which can lead to an unstable situation [29].

Third rail operational cost is less than diesel or steam locomotives, and they are more environmentally friendly $[30,31]$. The main advantage of third rails over the overhead wires is that they do not require construction to be conducted through the train path, which leads to lower costs $[32,33]$. Electric shock is the major disadvantage of 
Table 1 Major advantages and disadvantages of third rails

\begin{tabular}{ll}
\hline & Sources \\
\hline Third rail advantages & \\
Little visual intrusion on the environment & {$[30]$} \\
Less expensive installment procedure & {$[30]$} \\
No vertical clearance required & {$[33]$} \\
More robust than overhead line systems & {$[32,35]$} \\
Easy to reach and easy to maintain & {$[31]$} \\
Third rail disadvantages & \\
Speed limitation & {$[29]$} \\
Involves safety hazard & {$[34]$} \\
Limited capacity due to the low voltage & {$[27]$} \\
High voltage drop & {$[4]$} \\
Cannot be used for freight and high-speed trains & {$[28]$} \\
\hline
\end{tabular}

this system, but installing screen door platforms or placing the conductor rail away from the platform can solve this issue [34]. In third rail systems with top contact, snow is more likely to accumulate, which can cause interruptions in the operation of the system [35].

\subsection{Third Rail Issues and Challenges}

Several issues, including insulator failures, affect third rails in transit systems, and researchers have been investigating the reasons for their failure and have developed both preventative and remediation measures [7]. Third rail insulator failures usually occur inside the tunnels, where rust particles and carbon dust can cause a short circuit in the insulator, initiating smoke, exploding the insulator, and causing the wood ties to burn. Fiberglass insulators can burn under these circumstances, and porcelain insulators can melt [6]. The primary causes of issues with third rails are briefly described below.

In many parts of the world, including the USA, broken rails are the leading cause of train derailments [11]. Third rail system failures can be categorized by the weather, degradations, electrical erosion, corrosion, and distortions. Table 2 lists and describes these categories and the relative causes. Vandalism has also been recognized as a reason of third rail failure in some cases.

Weather conditions affect the operation of third rails, and their effects need to be mitigated [36]. Those with top contact are very prone to snow accumulation, which can cause interruptions, and thunderstorms with strikes of lightning can disable the power. Partial arcing in third rail systems is a result of degradation and can generate combustion and ignite flammable debris. Smoke from the ignited debris interrupts the third rail service and incurs safety risks as well. In some insulators, such as the BMC insulators, the accumulation of dust and brushes of carbon lead to deterioration and failure of the insulator [13]. Composite insulators might also fail to operate due to iron particulates, rust, etc. yielded from the maintenance tracks [37]. Degradation alters the normal functioning of polymeric insulators [5]. Reddy [13] conducted an analysis to determine the causes of degradation and arcing on insulators in dry, wet, and contaminated conditions, and the results interestingly showed that in wet conditions, the current leakage increased significantly: six times more than in dry conditions. Regular maintenance and coating mechanisms are suggested to increase the life and reduce the degradation of an insulator [5].

All third rail systems are susceptible to electrical erosion, which results from the arcing phenomenon between the rail contact and the collector shoe [13]. When there is repeated contact loss at a location on the face of the rail, erosion occurs at the conductor material. The conditions that can lead to collector loss include engagement and disengagement under full power at ramps, the collector's insufficient dynamic response, discontinuities in the surface of the rail contact, and poor alignment between the third rail and the running rails [13].

Corrosion is a challenge that must be addressed in any electrical supply system, including third rails. This is particularly true of DC systems [38]. The major factors that contribute to corrosion are moisture, competing fields of electricity, impedance bonds, and cab signal assets [38]. Distortion extension is widely relative to the ratio of distorting power to the power of the short circuit; therefore, even a small distortion can impact the voltage when the

Table 2 Major failure causes of third rail systems

\begin{tabular}{ll}
\hline Category & Causes \\
\hline Environmental & Erosion; Lightning; Sunlight; Salt For/Air; Saltwater Penetrating \\
Mechanical & Cracking/fracture; Mechanical stress; Damage from impact; Aging \\
Electrical & System voltage fluctuation; Corrosion; Distortion; Flashover/Arcing \\
Operational & Dirt build-up; Defective Product Materials; Water infiltration; Ice and snow accumulation; Vandalism \\
\hline
\end{tabular}


short-circuit power is low enough [11]. Supply voltage distortion, which is common in electrical systems that use capacitors, can be boosted by parallel resonances. Thus, the insulator's degradation due to these resonances is accelerated, and the reliability of the electrical components including the capacitors, cables, and transformers is reduced [20].

\section{Case Study Collection and Descriptive Data Analysis}

In this section, five third rail cases, each operated by a transit agency in the USA, are analyzed, and their preventive strategies are discussed in detail. Table 3 shows the characteristics of each of the third rails. Track engineers, directors, and other relative professionals from the selected case studies were contacted through phone and email for case study collection. These case studies were selected because of having large third rail systems for a long period of time and were located in different environmental areas.

As shown in Table 3, the system voltage commonly implemented in the studied cases was between 600 and $1000 \mathrm{~V}$. The most and least number of insulators in the selected transit agencies were 176,000 and 19,100, respectively. Porcelain, fiberglass, wood, and epoxy were used for the insulators, with porcelain being the most commonly used insulator material. Two of the selected agencies transit 100,000,000 passengers per year, while the other systems transport 50,000,000 passengers annually. Proportionally, case 3 , which only uses epoxy insulators, had the lowest rate of insulator failure $(1 / 50,000)$ and the second lowest operational cost per insulator failure (\$275). The average delay was 35 hours annually, while cases 1 and 5 experienced 10 hours of delays annually. Each case study is described below; the third rail features are discussed, and the adopted and potential preventive strategies are provided.

\subsection{Case Study 1}

The first selected transit agency is located in an area with warm summers, cold winters, and frequent short fluctuations in humidity and temperature. It provides public bus, heavy rail, and demand-responsive transportation services. The nominal traction power voltage of the third rail is $600-750 \mathrm{~V}$. Of the 176,000 insulators used by this transit system, 76,000 are porcelain, 60,000 are fiberglass, and 40,000 are wood. The rate of insulator failure is approximately 1 in 15,000, which causes an annual loss of 5000 passengers and a total delay of 10 hours per year. The insulators are installed with a clearance distance of six to ten inches around and above them. All of the contact rails are of the top-contact type. Of the 242 miles of contact rail in this system, 25 miles are steel, 5 miles are aluminum, and 212 miles are composite. The insulators are placed in the tunnels in a position that facilitates easy access for cleaning, but the cleaning process is labor-intensive and requires 3 weeks. Although safety requirements are considered, safety failures, such as smoke events that are due to traction fires and arcing insulators, occur. Damages to electrical propulsion equipment, poor track conditions due to electrolysis, and corrosion due to stray currents are some earlier failure events that occurred in this transit agency's third rail systems.

Table 3 General information of the case studies

\begin{tabular}{|c|c|c|c|c|c|}
\hline Variable & Case 1 & Case 2 & Case 3 & Case 4 & Case 5 \\
\hline System voltage (V) & $750-1000$ & $750-1000$ & $600-750$ & $600-750$ & $600-750$ \\
\hline Number of insulators & 176,000 & 19,100 & 140,000 & 134,000 & 72,000 \\
\hline Insulator material(s) & $\begin{array}{l}\text { Porcelain, fiberglass, } \\
\text { wood }\end{array}$ & $\begin{array}{l}\text { Porcelain, fiberglass, } \\
\text { epoxy }\end{array}$ & Epoxy & $\begin{array}{l}\text { Fiberglass, } \\
\text { porcelain }\end{array}$ & $\begin{array}{l}\text { Fiberglass, } \\
\text { porcelain }\end{array}$ \\
\hline Number of passengers per year & $100,000,000$ & $50,000,000$ & $50,000,000$ & $50,000,000$ & $100,000,000$ \\
\hline Insulator failure rate & $1 / 15,000$ & $1 / 1000$ & $1 / 50,000$ & $1 / 10,000$ & $1 / 5000$ \\
\hline $\begin{array}{l}\text { Loss of passengers (passengers/ } \\
\text { year) }\end{array}$ & 5000 & 1000 & 1000 & 1000 & 1000 \\
\hline Average annual delay (hours) & 10 & 35 & 20 & 20 & 10 \\
\hline Cost per insulator failure $(\$)$ & 400 & 400 & 275 & 375 & 250 \\
\hline Contact rail type & $\mathrm{TC}$ & $\mathrm{TC}$ & $\mathrm{TC}$ & $\mathrm{TC}$ & $\mathrm{TC} \& \mathrm{BC}$ \\
\hline Average insulator cost $(\$)$ & 300 & 350 & 75 & 75 & 75 \\
\hline
\end{tabular}

$T C$ top contact; $B C$ bottom contact 


\subsection{Case Study 2}

This transit agency is located in an area that has dry, warm summers and wet, mild winters and operates both heavy and light rail systems. The nominal traction power of this agency's third rail is $750-1000 \mathrm{~V}$, and it is comprised of 28 miles of steel top-contact rails. Its 19,100 insulators are made of fiberglass, porcelain, and epoxy, and the average annual insulator failure rate is approximately 0.001 , which leads to 35 hours of delays and a loss of 1000 passengers per year. Strain insulators are used most often, as they are less prone to fire, which is a major issue in third rail systems. For safety and cleaning purposes, a clearance space of 16-20 inches is provided around the insulators, and a safety cover, as well as brackets and anchors, surround them. A specialized pressure washer used for cleaning requires sufficient clearance around the insulator to facilitate cleaning the bottom. Several safety failures have occurred, including smoke events caused by arcing, damage to electrical propulsion equipment, and poor track conditions due to corrosion and electrolysis.

\subsection{Case Study 3}

The third case study provides subway, bus, commuter rail, ferry, and paratransit services to an area with a humid continental climate: warm summers, cold, snowy winters, and a large amount of precipitation. Even though all five of the major terrestrial mass transit vehicles are available, approximately $40 \%$ of the passengers are transited by the third rail system. All of the contact rails of the third rail system are made of composite and are the top-contact type, and $600-750 \mathrm{~V}$ provides the power.

The insulators are all made of epoxy and have an average annual failure rate of 0.001 , which leads the agency to anticipate an average of 20 hours of delay each year. Similar to many other transit agencies, 16-20 inches of clearance is provided around and above the insulators; however, covers, brackets, and anchors are not used to limit the access to the insulators, which leads to safety issues. No surface cleaning technologies are employed. The safety failures that have been observed in this system include smoke events due to arcing insulators, explosions due to flashovers on insulators, fires caused by electrical short circuits, and poor track conditions due to electrolysis and corrosion.

The rate of insulator failure in this transit system is lower than other studied systems even though a less expensive type of insulator and top contacts are implemented in this system, and no specific cleaning technology is used. However, this system is not as old as the other systems, and the geographical condition of the environment also does not lead to saltwater, snow, and ice accumulation.

\subsection{Case Study 4}

This agency operates transit services in a humid subtropical climate with hot and humid summers and cold winters. The mode of transit is heavy rail, with nominal traction power voltage of $600-750 \mathrm{~V}$. Its 134,000 insulators are made of porcelain and fiberglass, and the average rate of insulator failure is 0.0001 . A clearance space of $11-15$ inches is provided around each insulator. All of the contact rails are the top-contact type and are made of steel and composite. Iron particles, rust particles, carbon dust, and dirt are present in this system and may lead to the insulators failing. An average of 20 hours of delays is estimated to be due to insulator failures annually. A specialized crew is strategically placed for timely response to insulator arcing and fires that occur in the tunnels. Smoke events caused by arcing insulators and explosions caused by flashovers are the main safety failures.

\subsection{Case Study 5}

The fifth case study was of an agency that operates buses, rapid transit, commuter rail, light rail, and electric trolleybus services in a humid continental climate with hot and humid summers and cold winters. The nominal traction power voltage of the third rail system is $600-750 \mathrm{~V}$. Over 72,000 porcelain and fiberglass insulators are used in this system, and brackets, safety covers, and anchors are used to restrict access to them. The contact rails are made of steel and are of the bottom-contact and top-contact types. The average annual rate of insulator failure is 0.0002 , which causes a loss of approximately 1000 passengers and 10 hours of delays. The iron, rust, carbon particles/dust, dirt, and grime present in this third rail system can cause the insulators to fail.

\section{Comparative Analysis of Case Studies}

\subsection{Causes of Insulator Failures in Case Studies}

Insulator failure is a major concern for transit agencies, as they may lead to a partial, or even full, collapse of the system. Table 4 shows the percent of occurrence for each of the causes of rail system failure in the five case studies. The main impacts of insulator failures on the operation of a transit system are the manpower taken from normal maintenance duties, increased labor costs for emergency call-outs, and decreased retention of customers.

Environmental conditions that can increase the insulator failure rate, such as cold weather, humidity, water infiltration, and salt fog/air, were all present in case 1 . The insulators in this third rail system were susceptible to 
Table 4 Comparison of percentage of occurrence of third rail failure causes in the case studies

\begin{tabular}{|c|c|c|c|c|c|c|c|}
\hline ID & Insulator Failure Cause & Case 1 & Case 2 & Case 3 & Case 4 & Case 5 & Legend \\
\hline $\mathrm{FCl}$ & Dirt Build-up & O & O & O & 0 & O & $\bigcirc$ Never \\
\hline $\mathrm{FC} 2$ & Erosion & O & 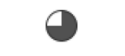 & $\bigcirc$ & $\bigcirc$ & $\bigcirc$ & () Infrequently \\
\hline $\mathrm{FC} 3$ & Cracking/Fracture & $\ominus$ & (1) & ( & 0 & $\ominus$ & Sometimes \\
\hline $\mathrm{FC} 4$ & Mechanical Stress & ๑ & 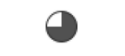 & O & $\bigcirc$ & 0 & Often \\
\hline $\mathrm{FC5}$ & System Voltage Fluctuation & $\ominus$ & $\Theta$ & (1) & O & (1) & Frequently \\
\hline FC6 & Damage from Impact & (1) & (1) & $\theta$ & $\bigcirc$ & ( & \\
\hline $\mathrm{FC} 7$ & Corrosion \& Fitting & (1) & (1) & O & $\bigcirc$ & $\bigcirc$ & \\
\hline FC8 & Flashover/Arcing & ( & ( & (1) & O & 0 & \\
\hline FC9 & Lightning & ( ) & O & O & O & $\mathrm{O}$ & \\
\hline $\mathrm{FC} 10$ & Salt Fog/Air & ( & (1) & $\mathrm{O}$ & $\mathrm{O}$ & O & \\
\hline FC11 & Defective Product/Material & ( & $\Theta$ & C & O & O & \\
\hline $\mathrm{FC} 12$ & Sunlight/UV & ( & (1) & 0 & O & $\bigcirc$ & \\
\hline $\mathrm{FC} 13$ & Snow \& Ice Accumulation & ( & ○ & O & 0 & $\bigcirc$ & \\
\hline FC14 & Vandalism & ( & O & O & O & $\bigcirc$ & \\
\hline $\mathrm{FC} 15$ & Aging & O & (1) & O & O & $\bigcirc$ & \\
\hline $\mathrm{FC} 16$ & Water Infiltration & 0 & O & 0 & O & 0 & \\
\hline $\mathrm{FC} 17$ & Saltwater & O & O & 0 & O & 0 & \\
\hline
\end{tabular}

corrosion, as they were exposed to rain and pollution, and created a low-resistance electrical path that could lead to fire. Dirt build-up and erosion were the most frequent causes of failure, while vandalism and aging were the least reported causes. Strain insulators were reported as the least likely to experience fires.

In case study 2, dirt build-up and damages resulting from impacts were the most frequent causes of failure. Vandalism and lightning were not observed as a cause of failure, and flashover/arcing was observed as occurring infrequently. Five types of such particles were present in case 2, including iron particles, rust particles, carbon dust, dirt, and grime. The insulators in the transit system of case study 3 were exposed to both wet and dry weather conditions, which can increase their failure rate. Water infiltration and dirt build-up were the most frequent causes of insulator failure; however, snow and ice accumulation, sunlight/UV, mechanical stress, salt fog/air, erosion, lightning, and vandalism were not recognized as being main causes of failure. In case study 4 , cracks/fractures and flashovers/arcing were the most frequent causes of insulator failures. They also failed due to stray currents, water infiltration, and weathering. Hot, dry weather were the basic environmental causes of insulator failures in this transit system, and dirt build-up and mechanical stress were also frequently observed causes of failure. Water infiltration in tunnels caused insulator failure by straying currents that led to flashovers.

Dirt build-up, erosion, and cracks/fractures were the most frequent contributors to insulator failures in all of the case studies. Many of the causes were weather-related, and appropriate strategies can resolve these issues and reduce the number of failures, delays, and additional costs. It is important for the agency to decide whether insulators are to be renewed or replaced before failure. Figure 4 shows a comparison of how the agencies in the case studies make that decision, based on the rate of operational cost of each insulator failure and the average renewal cost. As is shown, the operational cost per insulator failure is higher than average cost of the insulator itself for all of the third rail systems, but the differences vary.

In cases 1 and 2, the cost differences were $12.5 \%$ and $25 \%$, respectively, and in cases 3,4 , and 5 , the differences were $72 \%, 80 \%$, and $70 \%$, respectively. The variations occurred because of the different types of insulators used in each transit system, as well as differences in the economy, geographic location, etc. Overall, it can be concluded that renewal of the insulators before failure is the most costeffective choice than paying for operational costs after insulator failure. 
Fig. 4 Comparison of rate of operational cost of each insulator failure and average insulator renewal cost in the five case studies

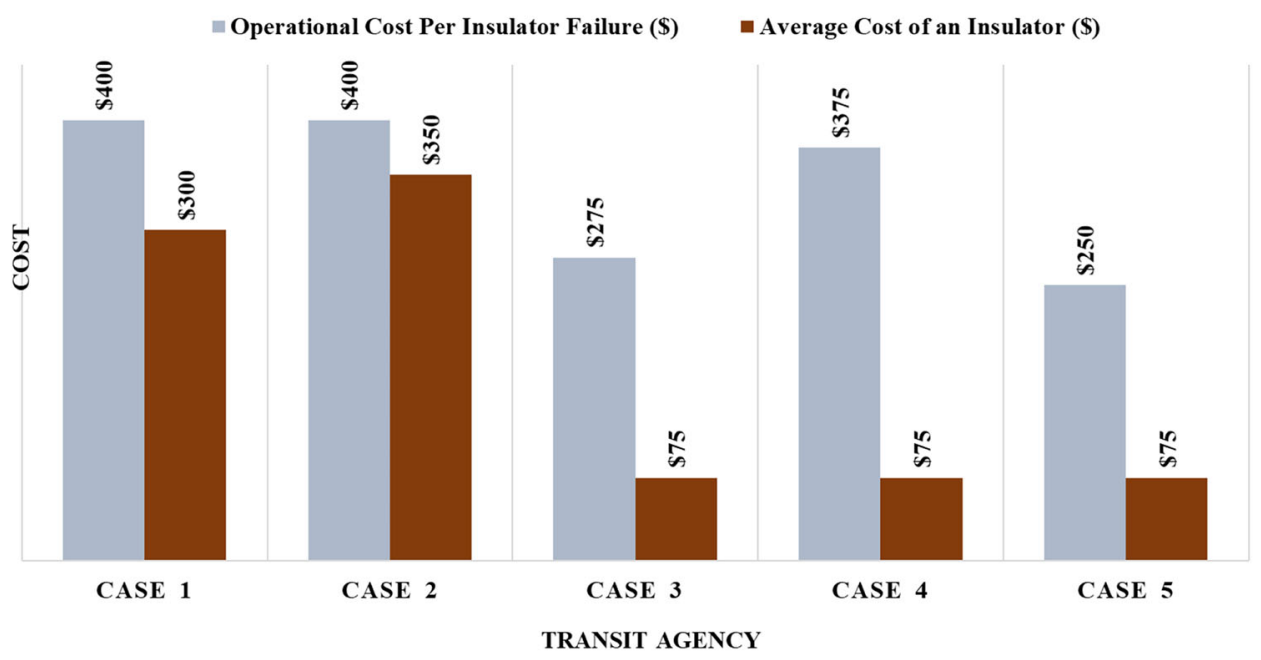

\subsection{Preventive Strategies Implemented in Case Studies}

Table 5 shows the causes of failure, the strategies that were used to resolve the issues, and how each is categorized. The 30 strategies are classified into three categories: (1) regular inspections; (2) preventive maintenance programs; and (3) regulation and safety. Each of the strategy categories is described below.

\subsubsection{Regular Inspections}

The regular inspection category includes eight strategies that can reduce the number of failures by detecting the components that are prone to fail. An inspection of the contact rail ensures that insulators are present; located on brackets; are exposed, with an insulator cap that is located by a lug hole; are clean, and are replaced if they are broken or chipped [5]. The contact rails and protection board brackets also need to be inspected regularly. The contact rails need to be inspected to ensure that they are exposed

Table 5 Preventive strategies and their categories for third rail failure causes

\begin{tabular}{|c|c|c|c|c|c|c|c|c|c|c|c|c|c|c|c|c|c|c|c|}
\hline \multirow{3}{*}{ Category } & & & \multicolumn{17}{|c|}{ Failure Cause } \\
\hline & ID & Strategy & \begin{tabular}{|l|}
$\overline{0}$ \\
\end{tabular} & ర્વ & \begin{tabular}{|l|}
8 \\
0
\end{tabular} & 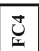 & 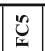 & $\begin{array}{l} \\
\end{array}$ & 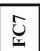 & \begin{tabular}{|l|} 
\\
0 \\
\end{tabular} & : & \begin{tabular}{|l|l|} 
\\
0
\end{tabular} & $\bar{z}$ & \begin{tabular}{|l|l|}
\multirow{2}{*}{} \\
\end{tabular} & \begin{tabular}{|l|l|}
\multirow{2}{*}{} \\
\end{tabular} & & \begin{tabular}{|l|l|}
$\frac{m}{2}$ \\
0 \\
0
\end{tabular} & \begin{tabular}{|l|}
0 \\
0 \\
0
\end{tabular} & $\bar{E}$ \\
\hline & S1 & Conduct detailed base corroded rail walking inspection & & & & & & & & & & + & & & & & & & \\
\hline \multirow{5}{*}{ 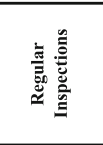 } & $\mathrm{s} 2$ & Conduct visual inspection at tunnels, espesifically at crossovers & & & & & & & & & & & & & & & & & \\
\hline & $\mathrm{S} 3 \mathrm{~S}$ & Conduct event-driven and post-incident inspection & & & & & & & & & & & & & & & & & \\
\hline & S4 & Use insulation testing and infrared or other new technologies & & & & & & & & & & & & & & & & & \\
\hline & \begin{tabular}{|l|ll}
$\mathrm{S} 5$ \\
\end{tabular} & Check regularly the insulation resistance, especially in tunnels & & & & & & & & & & & & & & & & & \\
\hline & \begin{tabular}{|l|ll}
56 \\
\end{tabular} & Conduct safety compliance inspections & & & & & & & & & & . & & & & & & & \\
\hline \multirow{11}{*}{ 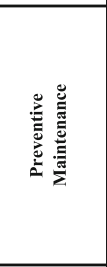 } & S7 & Renew and/or repair the aging third rail components & & & & & & & & & & & & & & & & & \\
\hline & \begin{tabular}{|c|cl}
58 \\
\end{tabular} & Replace aging transformers, DC rectifiers, and AC frequency converters & & & & & & & & & & & & & & & & & \\
\hline & \begin{tabular}{|c|c|c|c|}
59 \\
\end{tabular} & Replace aging electrical gear & & & & & & & & & & & & & & & & & \\
\hline & S10 & Replace/repair failed, damaged, and stolen components & & & & & & & & & & & & & & & & & \\
\hline & S11 & Use cathodic protection & & & & & & & & & & & & & & & & & \\
\hline & S12 & Clean surface regularly & & & & & & & & & & - & & & & & & & \\
\hline & $\$ 13$ & Use adjustable cleaning devices & & & & & & & & & & & & & & & & & \\
\hline & S14 & Clean power components regularly & & & & & & & & & & & & & & & & & \\
\hline & S15 & Clean insulator regularly & & & & & & & & & & & & & & & & & \\
\hline & S16 & Develop and implement insulator failure prediction models & & & & & & & & & & & & & & & & & \\
\hline & S17 & Use maintenance management tracking software & & & & & & & & & & & & & & & & & \\
\hline \multirow{13}{*}{ 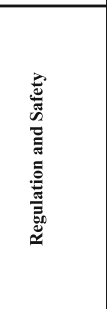 } & S18 & Improve and upgrade safety standards regularly & & & & & & & & & & & & & & & & & \\
\hline & S19 & Document and consider previous failures' lessons learned & & & & & & & & & & & & & & & & & \\
\hline & S20 & Develop specifications for the third rail contact system & & & & & & & & & & & & & & & & & \\
\hline & S21 & Consider clearance above and around insulators & & & & & & & & & & & & & & & & & \\
\hline & S22 & Install protection board & & & & & & & & & & & & & & & & & \\
\hline & S23 & Install third rail cover board & & & & & & & & & & & & & & & & & \\
\hline & S24 & \begin{tabular}{|l|l|l} 
Install third rail anchor \\
\end{tabular} & & & & & & & & & & & & & & & & & \\
\hline & S25 & Use Strain insulators where fire of insulators is common & & & & & & & & & & & & & & & & & \\
\hline & S26 & Consider safety considerations, specifically electrical safety & & & & & & & & & & & & & & & & & \\
\hline & S27 & Use third rail heaters & & & & & & & & & & & & & & & & & \\
\hline & S28 & Improve and upgrade design methods & & & & & & & & & & & & & & & & & \\
\hline & S29 & Implement insulator configurations that enable cleaning and maintenance & & & & & & & & & & & & & & & & & \\
\hline & S30 & Develop and implement specific insulator installment specifications & & & & & & & & & & & & & & & & & \\
\hline
\end{tabular}


uniformly and evenly on all of the insulators and to detect damages on the contact surface. The protection board brackets for the timber ties should be inspected to verify that the brackets are located on the timber ties, are accurately gaged, are exposed on the tie, bolted by screws, and installed correctly on the running rail [8].

Inspections vary with the individual tasks and conditions. For example, visual inspections are important for wood insulators to detect any signs of deterioration but would not be helpful for other types of insulators. Inspections also can be performed for a specific purpose, such as for checking insulation resistance or detecting corrosion. The internal, detailed, visual, event-driven, post-incident, and walked-track inspections can be performed at intervals that range from daily to biannually. Safety compliance inspections were conducted every 6 months or annually in the case studies. Most of the strategies of this category were designed to prevent failures; however, the "detailed base-corroded rail walking inspection" (S1) is conducted to control corrosion (FC7), and "regular check of the insulation resistance" (S5) alleviates system voltage fluctuations (FC5) and flashovers/arcing (FC8).

\subsubsection{Preventive Maintenance Programs}

This category consists of 11 strategies that are implemented to control and improve the performance of third rail systems and reduce the number of failures. For example, in all the studied transit systems, maintenance crews are dedicated to cleaning the insulators and power components in the tunnels and walkways. Aging, damaged, failed, and stolen components can be detected during the inspections and maintenance programs, so that they can be replaced or repaired. A statistical method and historical data can be used as a preventative action to develop a prediction model that identifies insulators that may fail in the near future.

The cleaning of surfaces (S12), power components (S14), and insulators (S15) can reduce the build-up of dirt (FC1), voltage fluctuations (FC5), and snow and ice accumulation (FC13), and are very important to avoiding third rail issues. The device used for cleaning the insulators should adjust to different insulator sizes to make the task easier and more effective. The occasional injuries that occur due to manual cleaning could be eliminated by adopting automated cleaning. Using cathodic protection (S11) is a useful method for insulating the third rail components from weather effects such as erosion (FC2), corrosion (FC7), salt fog (FC10), sunlight (FC12), water infiltration (FC16), and saltwater (FC17), and alleviates most causes of failure in this category. In addition, using maintenance management tracking software (S17) can assist in tracking the preventative maintenance and optimize the inherent costs.

\subsubsection{Regulation and Safety}

This is the largest category and includes most of the preventive strategies for failure and provides continual improvement to the systems' reliability. The safety standards and regulations for third rails in the case studies are updated every 4-5 years (S18). Design methods also need to be upgraded according to the new technologies and improvements (S28).

To avoid repeating the same mistakes and make better use of time and money spent on the system, it is advisable to document the important practices and lessons learned from failures (S19). Specifications should be developed for the third rail components such as the contact system (S20) and insulators (S30), defining the requirements for accurate installment and ultimate functioning. Specifications for safety considerations (S26) also should be developed to ensure the safety level of the system and prevent safety failures, such as smoke events, due to the arcing of insulators. The installation of protection boards (S22) addresses several failure causes in this category, including erosion, (FC2), cracking (FC3), mechanical stress (FC4), damage from impact (FC6), lightning (FC9), sunlight (UV) (FC12), water infiltration (FC16), and saltwater (FC17). In fact, the studied transit systems use cover boards to preserve their components from many environmental hazards and consequently from failure. Using heaters to prevent third rails from icing is one of the strategies that will help avert the weather-related issues for third rail systems.

\section{Discussion}

The average annual number of insulator failures in the five case studies in this research was ten failures, which led to delays in these third rail systems. Considering the fact that the average cost of an insulator is around \$280, implementing appropriate strategies would prevent the loss of almost 1000 passengers who prefer not to use third rail transit systems due to the abovementioned delays. Furthermore, removing dirt built-up as the most frequent cause of insulator failure needs to be taken seriously for reducing insulator failures in third rail systems. On the other hand, while the age, quality, and cleaning of the insulators are important factors in reducing the rate of insulator failures in third rail systems, in some of the studied transit systems, the rate of failure is low, even though part of these factors are not satisfied. The results demonstrate that in these transit systems, implementing appropriate strategies leads to a minimum of insulator failures, which confirms the importance of utilizing proper preventive strategies. In addition, the geographical conditions of the transit systems need to be considered prominently while choosing the 
preventive strategies for reducing insulator failures in third rail systems.

To improve the reliability of third rail systems, using new maintenance technologies and managing the collected database using artificial intelligence (AI) or machine learning (ML) techniques can be helpful. For instance, installing sensors on the insulators in order to collect realtime data and assimilating the collected data for modelling the failure procedure of insulators can help managers prevent probable occurrence of insulator failures and avoid corresponding delays in the third rail systems. However, these data-based techniques and tools need to be cost-effective compared to the cost of delays to encourage transit agencies to adopt and implement these advanced technologies.

\section{Conclusions}

Third rail systems are implemented in many transit systems globally and are characterized by the power being supplied by a third rail. In this research, different characteristics of third rails were comprehensively investigated, third rail insulator failure causes were identified, and relative preventive strategies were developed and categorized. A thorough content analysis of the literature was performed, and five case studies were investigated and analyzed. Data related to third rail components and their arrangement, advantages and disadvantages, challenges, insulator failures, and strategies employed to mitigate or prevent common problems was collected, compared, and analyzed. The results revealed that conducting maintenance and inspections at predetermined intervals can help prevent insulator failures in third rail systems. It was concluded that the performance of third rails and insulators initially depends on local environmental conditions, and dirt build-up is the most common cause of insulator failures. According to the five case studies, the following are the most common of the 30 preventive best practices: (1) regular visual inspections; (2) regular cleaning of insulators, surfaces, and other components; (3) insulator testing; and (4) renewal of the failed components. In addition, it was concluded that renewal of the insulators before failure is more cost-effective than paying for operational costs after an insulator failure.

The strategies were classified into three categories: regular inspections; preventive maintenance programs; and regulation and safety. The regular inspection category was adopted most often by the transit agencies. Some of the agencies are testing new insulator materials to reduce the failure rates of insulators; however, most of those in the case studies were made of porcelain or fiberglass. The outcomes of this research can be useful to transit experts and practitioners in evaluating the current status of their third rail systems and in adopting preventive strategies to reduce the number of third rail insulator failures.

Acknowledgments This research project was sponsored by Transit Cooperative Research Program (TCRP project J-07/Topic SD-05 Third Rail Insulator Failures). The authors gratefully acknowledge the support and generosity of the sponsor, without which the present study could not have been completed. Also, the authors would like to thank Ms. Zara Farooq Khan who helped us to collect data for conducting this research.

Authors' Contributions The authors confirm contribution to the paper as follows: study conception and design: BR, SK; analysis and interpretation of results: BR; draft manuscript preparation: BR. All authors reviewed the results and approved the final version of the manuscript.

Funding This study is sponsored and supported by Transit Cooperative Highway Research Program (TCRP) project J-07/Task SD-05.

\section{Declarations}

Conflict of interest All authors declare that hthey have no conflict of interest.

Open Access This article is licensed under a Creative Commons Attribution 4.0 International License, which permits use, sharing, adaptation, distribution and reproduction in any medium or format, as long as you give appropriate credit to the original author(s) and the source, provide a link to the Creative Commons licence, and indicate if changes were made. The images or other third party material in this article are included in the article's Creative Commons licence, unless indicated otherwise in a credit line to the material. If material is not included in the article's Creative Commons licence and your intended use is not permitted by statutory regulation or exceeds the permitted use, you will need to obtain permission directly from the copyright holder. To view a copy of this licence, visit http://creativecommons. org/licenses/by/4.0/.

\section{References}

1. Hill RJ (1997) Electric railway traction. Part 7: electromagnetic interference in traction systems. Power Eng. J. 11(6):259-266

2. ASCE (American Society of Civil Engineers) (2017), Infrastructure Report Card. Asce, Reston, VA, USA. See http://www. infrastructurereportcard.org. Accessed $20 \mathrm{Feb} 2020$

3. Montesinos J, Gorur RS, Mobasher B, Kingsburry D (2018) Brittle fracture in non-ceramic insulators: electrical aspects of microscopic flaws in glass reinforced plastic (GRP) rods. IEEE Trans Dielectr Electr Insul 9(2):244-252

4. Stewart E, Weston P, Hillmansen S, Roberts C (2011) Using bogie-mounted sensors to understand the dynamics of third rail current collection systems. Proc Inst Mech Eng Part F J Rail Rapid Transit 225(2):219-227

5. Verma AV, Reddy BS (2018) Tracking and erosion resistance of LSR and HTV silicone rubber samples under acid rain conditions. IEEE Trans Dielectr Electr Insul 25(1):46-52

6. Vohra A (2004) Cleaning device for electrified third rail insulators. Transit IDEA Project Rep 36:19

7. Kumosa M, Kumosa L, Armentrout D (2004) Causes and potential remedies of brittle fracture failure of composite non- 
ceramic insulators. IEEE Trans Dielectr Electr Insul 11(6): 1037-1048

8. Vohra A (2008) Cleaning device for electrified third rail insulators-phase 2. No Transit IDEA Project 47:61

9. Mobasher B, Kingsbury DMJ, Gorur RS (2002) Brittle fracture in nonceramic insulators: mechanical aspects of crimped glass reinforced plastic (GRP) rods. IEEE Trans Dielectr Electr Insul 9:236-243

10. Ibrahem, A (2017) Leakage current detection and protection for electrical railway systems. M.Sc. thesis

11. Cherney EA, Gorur RS, Krivda A, Jayaram SH, Rowland SM, Li S, Marzinotto M, Ghunem RA, Ramirez I (2015) DC inclinedplane tracking and erosion test of insulating materials. IEEE Trans Electr Insul 22:211-217

12. Papailiou KO, Schmuck F (2012) Silicone composite insulators: materials, design, applications. Springer, Berlin

13. Reddy S (2019) Failure analysis of BMC insulators used for third rail traction system. Eng Fail Anal 101:1-8

14. Forman KG (2013) Aluminum/stainless steel conductor technology: a case for its adoption in the US. In: Proceedings of the ASME Joint Rail Conference 2013. American Society of Mechanical Engineers Digital Collection, Berlin

15. Brenna M, Foiadelli F, Kaleybar HJ (2020) The evolution of railway power supply systems toward smart microgrids: the concept of the energy hub and integration of distributed energy resources. IEEE Electrif Mag 8(1):12-23

16. Mariscotti A (2019) Normative framework for the assessment of the radiated electromagnetic emissions from traction power supply and rolling stock. In: IEEE vehicle power and propulsion conference (VPPC), pp 1-7

17. Cintolesi B, Mariscotti A, Merlo D, Mari M (2010) Modeling the magnetic field emissions from a third rail system. In: Electrical systems for aircraft, railway and ship propulsion, pp 1-5

18. Kermanshachi S, Rouhanizadeh B (2020). Third rail insulator failures: current state of the practice. In: TCRP synthesis of transit practice, (Project J-7, Topic SD-05)

19. Rouhanizadeh B, Kermanshachi S (2020) Third-rail insulator failure causes and mitigating practices: a comparative study of multiple case studies in the US. Urban Rail Transit 6(4):205-217

20. Gorur RS, Cherney EA, Burnham JT (1999) Outdoor insulators. Ravi S Gorur Inc., London

21. Pradier JC, Pinard F (2020). U.S. Patent No. 10,554,000. Washington, DC: U.S. Patent and Trademark Office

22. Steininger R (2020) U.S. Patent No. 10,596,921. Washington, DC: U.S. Patent and Trademark Office

23. Wu G, Gao, G, Wei W, Yang Z (2019) The current collection approach of high-speed train — pantograph and catenary system. In: The electrical contact of the pantograph-catenary system, pp 1-16

24. Cha YH, Mei Y, Olofsson U (2016) Airborne wear particles generated from conductor rail and collector shoe contact: influence of sliding velocity and particle size. Tribol Lett 64(3):40
25. Khodaparastan M, Mohamed A (2019) Modeling and simulation of a reversible substation for recuperation of regenerative braking energy in rail transit systems. In: IEEE transportation electrification conference and expo (ITEC), pp 1-5

26. Wootton M (2018) Experimental analysis of electric double layer and lithium-ion capacitors for energy storage systems and their application in a simulated dc metro railway system. Ph.D., dissertation

27. Green S, Hickson D, Ward D, Roberts C, Weston P, Stewart E (2011) Monitoring the DC third rail interface using an in-service train. In: Paper presented at the 5th IET conference on railway condition monitoring and nondestructive testing; Birmingham, UK

28. Li X, Lo HK (2014) An energy-efficient scheduling and speed control approach for metro rail operations. Transp Res Part B Methodol 64:73-89

29. Hobbs I (2007) High speed power [rail electrification]. Power Eng 21(2):32-35

30. Solomon G (2016) Analysis of third rail technology for 750 V DC power feeder light railway transportation: case study of AALRT. Ph.D., dissertation, Addis Ababa University

31. Dutta O, Saleh M, Khodaparastan M, Mohamed A (2020) A dualstage modeling and optimization framework for wayside energy storage in electric rail transit systems. Energies 13(7):1614

32. Kanz KG, Kay MV, Biberthaler P, Russ W, Wessel S, Lackner CK, Mutschler W (2004) Susceptibility of automated external defibrillators to train overhead lines and metro third rails. Resuscitation 62(2):189-198

33. Frey S (2012) Railway electrification. White word publications, Oxford

34. Fridolf K, Nilsson D, Frantzich H (2016) Evacuation of a metro train in an underground rail transportation system: flow rate capacity of train exits, tunnel walking speeds and exit choice. Fire Technol 52(5):1481-1518

35. Wang M, Yang X, Zheng TQ, Ni M, Guo W (2020) Performance evaluations of DCAT position for the floating DCAT system in DC railways. In: Proceedings of the 4th international conference on electrical and information technologies for rail transportation (EITRT): novel traction drive technologies of rail transportation, pp 557-567

36. Venkatesulu B, Thomas MJ (2011) Long-term accelerated weathering of outdoor silicone rubber insulators. IEEE Trans Dielectr Electr Insul 18(2):418-424

37. Hu Z, li, W. Lin, Y. (2006) Present and future development of detection methods for composite insulator. Insul Surge Arresters 8(1):133-137

38. Luder D, Ariely S, Yalin M (2019) Stress corrosion cracking and brittle failure in a fiber-reinforced plastic (FRP) insulator from a $400 \mathrm{kV}$ transmission line in humid environment. Eng Fail Anal 95:206-213 